Correspondence

Wonyong Kim

kimwy@cau.ac.kr
Received 23 November 2009 Accepted 4 July 2010

\section{Identification of the cpsA gene as a specific marker for the discrimination of Streptococcus pneumoniae from viridans group streptococci}

Hee Kuk Park, ${ }^{1,2}$ † Sang-Jae Lee, ${ }^{3}$ † Jang Won Yoon, ${ }^{1,2}$ Jong Wook Shin, ${ }^{4}$ Hyoung-Shik Shin, ${ }^{3}$ Joong-Ki Kook, ${ }^{5}$ Soon Chul Myung ${ }^{2,6}$

and Wonyong $\mathrm{Kim}^{1,2}$

\author{
${ }^{1}$ Department of Microbiology, Chung-Ang University College of Medicine, 221 Heukseok-dong, \\ Dongjak-gu, Seoul 156-756, Republic of Korea \\ ${ }^{2}$ Research Institute for Translational System Biomics, Chung-Ang University College of Medicine, \\ 221 Heukseok-dong, Dongjak-gu, Seoul 156-756, Republic of Korea \\ ${ }^{3}$ Department of Periodontology, Wonkwang University College of Dentistry, Iksan 570-749, \\ Republic of Korea \\ ${ }^{4}$ Department of Internal Medicine, Chung-Ang University College of Medicine, 221 Heukseok-dong, \\ Dongjak-gu, Seoul 156-756, Republic of Korea \\ ${ }^{5}$ Department of Biochemistry, Chosun University College of Dentistry, Gwangju 501-825, Republic \\ of Korea \\ ${ }^{6}$ Department of Urology, Chung-Ang University College of Medicine, 221 Heukseok-dong, \\ Dongjak-gu, Seoul 156-756, Republic of Korea
}

\begin{abstract}
Streptococcus pneumoniae, the aetiological agent of pneumonia and non-gonococcal urethritis, shares a high degree of DNA sequence identity with the viridans group of streptococci, particularly Streptococcus mitis and Streptococcus oralis. Although their clinical and pathological manifestations are different, discrimination between $S$. pneumoniae and its close viridans cocci relatives is still quite difficult. Suppression subtractive hybridization was performed to identify the genomic differences between $S$. pneumoniae and S. mitis. Thirty-four resulting S. pneumoniaespecific clones were examined by sequence determination and comparative DNA sequence analysis using BLAST. S. pneumoniae-specific primers were subsequently designed from one of the clonal DNA sequences containing the cps gene (coding for capsular polysaccharide biosynthesis). The primer specificities were evaluated using 49 viridans streptococci including 26 S. pneumoniae, 54 other streptococci, 14 Lactococcus species, 14 Enterococcus species and three Vagococcus species, and compared with the specificities of previously described autolysin (lytA), pneumolysin ( $p / y)$, Spn9802 and Spn9828 primers. The newly designed cpsA-specific primer set was highly specific to $S$. pneumoniae and was even better than the existing primers. These findings may help improve the rapid identification and differentiation of $S$. pneumoniae from closely related members of the viridans group streptococci.
\end{abstract}

\section{INTRODUCTION}

Streptococcus pneumoniae is an important pathogen associated with various human diseases such as pneumonia, non-gonococcal urethritis, otitis media, septicaemia and meningitis (Whatmore et al., 2000). In contrast, two viridans group streptococci, Streptococcus oralis and Streptococcus mitis, cause dental caries and

†These authors contributed equally to this work.

Abbreviation: $\mathrm{SSH}$, suppression subtractive hybridization. endocarditis and are usually considered commensal microorganisms of the oral cavity (Dyson et al., 1999; Willcox et al., 1988). Because S. pneumoniae is often isolated with $S$. mitis and S. oralis, accurate discrimination between these strains is important for proper diagnosis and treatment of S. pneumoniae.

In recent years, molecular genetic analyses based on the $16 \mathrm{~S}$ rRNA gene have provided a potent means of characterization at the species level (Fox et al., 1992; Stackebrandt et al., 1991; Stackebrandt \& Goebel, 1994). Unfortunately, S. pneumoniae shares over $99 \% 16 \mathrm{~S}$ rRNA gene identity with 
S. mitis and S. oralis (Suzuki et al., 2005), complicating molecular identification among them. Several molecular assays have been developed to identify $S$. pneumoniae from the other viridans group streptococci using primers specific to pneumococcal virulence factors such as genes encoding pneumolysin (ply) (Corless et al., 2001), autolysin (lytA) (McAvin et al., 2001), pneumococcal surface antigen A (Morrison et al., 2000), manganese-dependent superoxide dismutase (Kawamura et al., 1999) and penicillin-binding protein (O’Neill et al., 1999).

Recently, real-time PCR methods have improved the detection of these organisms (Abdeldaim et al., 2008; Carvalho et al., 2007; Corless et al., 2001; Suzuki et al., 2006). At the same time, increasing evidence suggests the possible occurrence of lateral gene transfer among the naturally transformable viridans group streptococci. Indeed, some pneumococcal virulence genes of $S$. pneumoniae have occasionally been detected in S. mitis or S. oralis isolates (Seki et al., 2005; Verhelst et al., 2003; Whatmore et al., 2000).

Previously, two genomic clones specific to S. pneumoniae, referred as to Spn9802 and Spn9828, were identified by genomic subtractive hybridization (Suzuki et al., 2005). A few false-positive results were reported, however, from samples where $S$. pneumoniae was not isolated (Abdeldaim et al., 2008; Suzuki et al., 2006).

Suppression subtractive hybridization ( $\mathrm{SSH}$ ) is a powerful tool for searching for genomic differences among closely related strains (Kim et al., 2008) or for identifying novel virulence factors by genomic comparison of pathogenic and non-pathogenic strains (Agron et al., 2002). In this study, SSH was used to identify novel genomic markers specific to $S$. pneumoniae, allowing accurate discrimination of $S$. pneumoniae from members of the closely related viridans group streptococci.

\section{METHODS}

Bacterial strains. A total of 134 bacterial strains were used in this study (Table 1). The $26 \mathrm{~S}$. pneumoniae strains were obtained from the Korean Collection for Type Cultures (KCTC; Daejeon, Korea), the Culture Collection of Antibiotic-resistant Microbes (CCARM; Seoul, Korea) and the Department of Oral Biochemistry, College of Dentistry, Chosun University (ChDC; Gwangju, Korea). The remaining 108 reference Streptococcus strains were obtained from the Culture Collection of the University of Gothenburg (CCUG; Gothenburg, Sweden), the American Type Culture Collection (ATCC; Manassas, VA, USA), the Deutsche Sammlung von Mikroorganismen und Zellkulturen (DSMZ; Braunschweig, Germany), the Belgian Coordinated Collections of Micro-organisms (BCCM/LMG; Gent, Belgium), the ChDC or the KCTC.

Genomic DNA preparation. Each bacterial strain was grown on either $5 \%$ sheep blood agar (Difco) for oral streptococci strains or brain-heart infusion agar (Difco) for the other strains at $37^{\circ} \mathrm{C}$ for $20 \mathrm{~h}$. Genomic DNA was extracted from $1.4 \mathrm{ml}$ bacterial culture using a cetyltrimethylammonium bromide method (Ausubel et al., 1993). Purified DNA was dissolved in sterile water with $40 \mu \mathrm{g}$ RNase
$\mathrm{A} \mathrm{ml}^{-1}$ and quantified using an Infinite 200 NanoQuant (Tecan) at a wavelength of $260 \mathrm{~nm}$.

Construction of the SSH library. SSH was performed with $S$. pneumoniae KCTC $5080^{\mathrm{T}}$ as the tester genomic DNA and the most closely related Streptococcus species, S. mitis KCTC $3556^{\mathrm{T}}$, as the driver genomic DNA. The SSH library was generated using a PCR-Select Bacterial Genome Subtraction kit (Clontech) as described previously (Akopyants et al., 1998). Briefly, both tester and driver genomic DNAs were digested with the restriction enzyme RsaI (New England Biolabs) at $37{ }^{\circ} \mathrm{C}$ for $2 \mathrm{~h}$ to obtain DNA fragments smaller than $3.0 \mathrm{~kb}$. Two different adaptors were separately ligated to the $5^{\prime}$ end of the restricted tester DNA fragments: one with adaptor 1 (5'-CTAATACGACTCACTATAGGGCTCGAGCGGCCGCCCGGGCAGGT-3' and 3'-GGCCCGTCCA- $\left.5^{\prime}\right)$ and the other with adaptor $2 \mathrm{R}\left(5^{\prime}\right.$-CTAATACGACTCACTATAGGGCAGCGTGGTCGCGGCCGAGGT-3' and $3^{\prime}$-GCCGGCTCCA $\left.-5^{\prime}\right)$. Two hybridizations were performed. In the first hybridization, the restricted driver DNA fragments were added to each adaptor-linked tester DNA fragment (ratio 4:1). The resultant two driver/adaptor DNA mixtures were denatured at $98{ }^{\circ} \mathrm{C}$ for $1.5 \mathrm{~min}$, annealed at $42{ }^{\circ} \mathrm{C}$ for $1.5 \mathrm{~h}$ and then mixed together before the second hybridization. Five hundred nanograms of the driver genomic DNA was added to the combined DNA mixture before the second hybridization, which was carried out at $42{ }^{\circ} \mathrm{C}$ for $16 \mathrm{~h}$. Using the adaptor-specific primer (5'-CTAATACGACTCACTATAGGGC-3'), the tester-specific DNA fragments were amplified by two sequential nested PCRs, as only the unhybridized tester DNA sequences should reassociate to form double-stranded tester DNA fragments ligated to two different adaptors. The resultant PCR products were ligated into the pCR2.1-TOPO vector system (Invitrogen) and transformed into One Shot TOP10 E. coli strains (Invitrogen). The transformants were plated onto Luria-Bertani medium containing ampicillin/IPTG/X-Gal and white colonies were screened for the insert fragment. Colony PCR with the nested primers 1 ( $5^{\prime}$-TCGAGCGGCCGCCCGGGCAGGT- $3^{\prime}$ ) and 2R ( $5^{\prime}$-AGCGTGGTCGCGGCCGAGGT-3') was used to confirm the presence of the insert DNA fragments by agarose gel electrophoresis.

Reverse Southern dot-blot analysis. All putative clones were subjected to differential dot-blot analysis to verify whether they were specific for the tester genomic DNA. Briefly, $25 \mu \mathrm{l}$ of equal amounts of each DNA sample were dotted in duplicate onto positively charged Hybond- $\mathrm{N}^{+}$nylon membranes (Amersham Biosciences). DNA samples were exposed to $1000 \mathrm{~mJ}$ UV for $3.5 \mathrm{~min}$ in a Stratalinker (Stratagene). DNA probes were prepared with the RsaI-digested genomic DNA of each strain (S. pneumoniae KCTC $5080^{\mathrm{T}}$ and S. mitis KCTC $3556^{\mathrm{T}}$ ) using an ECL Direct Nucleic Acid Labelling and Detection System (Amersham Biosciences). The probe was used for each of the duplicate membranes. Pre-hybridization and hybridization were carried out according to the manufacturer's instructions (Amersham Biosciences). The membrane was exposed to Hyperfilm ECL (Amersham Biosciences) for visualization.

DNA sequencing and analysis. Each clone was sequenced in duplicate with M13 forward (-20) and/or reverse primers using a BigDye Terminator Cycle Sequencing kit and an ABI PRISM 3100 automated DNA sequencer (Applied Biosystems). Sequence assembly and further editing were performed with CLUSTAL_X (Thompson et al., 1997). The nucleotide sequence identities of the genomic subtracted fragments of $S$. pneumoniae KCTC $5080^{\mathrm{T}}$ were determined using the BLASTX program available on the BLAST network service of the National Center for Biotechnology Information.

Design of PCR primers and PCR conditions. Oligonucleotide primer sets specific to $S$. pneumoniae were designed using Primer3 software (Rozen \& Skaletsky, 2000) based on a 492 bp sequence of the cPsA gene from one of the SSH clones. The reaction conditions were optimized using a TGradient Thermal Cycler (Biometra). The lytA, ply, 
Table 1. Streptococcus species and other bacteria $(n=134)$ used in this study

T, Type strain.

\begin{tabular}{|c|c|c|}
\hline Group & Species & Strain \\
\hline \multirow[t]{4}{*}{ S. viridans $(n=49)$} & S. pneumoniae & $\begin{array}{l}\text { KCTC } 5080^{\mathrm{T}} \text {, CCARM 4009, CCARM 4019, CCARM 4033, CCARM 4109, } \\
\text { CCARM 4112, CCARM 4113, CCARM 4114, CCARM 4115, CCARM 4003, } \\
\text { CCARM 4005, CCARM 4078, CCARM 4079, CCARM 4080, CCARM 4084, } \\
\text { CCARM 4085, CCARM 4088, CCARM 4106, CCARM 4116, ChDC 4-0134, } \\
\text { ChDC 4-0749, ChDC 6-4740, CCARM 4081, CCARM 4091, CCARM 4111, } \\
\text { CCARM 4059 }\end{array}$ \\
\hline & S. pseudopneumoniae & CCUG $49455^{\mathrm{T}}$, CCUG 48465 \\
\hline & S. mitis & $\begin{array}{l}\text { KCTC } 3556^{\mathrm{T}} \text {, ChDC B183, ChDC B186, ChDC B193, ChDC B194, ChDC B227, } \\
\text { ChDC B231, ChDC B239, ChDC B242, ChDC B253, ChDC B258, ChDC B260, } \\
\text { ChDC B279, ChDC B286, ChDC B303-1, ChDC B315, ChDC B317 }\end{array}$ \\
\hline & S. oralis & KCTC $13048^{\mathrm{T}}$, ATCC 9811, DSM 20379, DSM 20066 \\
\hline \multirow[t]{7}{*}{ Other Streptococcus spp. $(n=54)$} & S. pyogenes & КСТC $3984^{\mathrm{T}}$, КСТС 3096, КСТC 3208 \\
\hline & S. gordonii & KCTC $3286^{\mathrm{T}}$, ChDC B180, ChDC B211, ChDC B216, ChDC B241 \\
\hline & S. sanguinis & $\begin{array}{l}\text { KCTC } 3284^{\mathrm{T}} \text {, ChDC B203, ChDC B219, ChDC B304-1, ChDC B304-2, ChDC } \\
\text { B304-3, ChDC B305-1, ChDC B305-2, ChDC YSA1 }\end{array}$ \\
\hline & S. parasanguinis & $\begin{array}{l}\text { KCTC } 13046^{\mathrm{T}} \text {, ChDC B185, ChDC B195, ChDC B212, ChDC B213, ChDC B215, } \\
\text { ChDC B217, ChDC OS49 }\end{array}$ \\
\hline & S. constellatus & ATCC $27823^{\mathrm{T}}$, ChDC B280, ChDC B284, ChDC B290 \\
\hline & S. intermedius & KCTC $3268^{\mathrm{T}}$, ChDC KB80, ChDC KB236, ChDC KB717 \\
\hline & S. anginosus & $\begin{array}{l}\text { ATCC 33397, ChDC YA1, ChDC YA3, ChDC YA5, ChDC YA6, ChDC YA7, } \\
\text { ChDC YA8, ChDC YA9, ChDC YA10, ChDC YA11, ChDC YA12, ChDC YA13, } \\
\text { ChDC B181, ChDC YA201, ChDC B232, ChDC B248, ChDC B252, ChDC B263, } \\
\text { ChDC B287, ChDC B311, ChDC B407-1 }\end{array}$ \\
\hline \multirow[t]{23}{*}{ Other coccus species $(n=31)$} & L. plantarum & DSM $20686^{\mathrm{T}}$ \\
\hline & L. lactis subsp. cremoris & DSM $40699^{\mathrm{T}}$ \\
\hline & L. lactis subsp. hordniae & KCTC $3768^{\mathrm{T}}$ \\
\hline & L. piscium & KCTC $3639^{\mathrm{T}}$ \\
\hline & L. garvieae & KCTC $3772^{\mathrm{T}}$, LMG 8162, LMG 8501, LMG 9472, LMG 14494 \\
\hline & L. lactis subsp. lactis & KCTC $3769^{\mathrm{T}}$, КСТC 3191, КСТC 2013, КСТC 3894, КСТC 3926 \\
\hline & E. solitarius & KCTC $3553^{\mathrm{T}}$ \\
\hline & E. hirae & KCTC $3616^{\mathrm{T}}$ \\
\hline & E. mundtii & KCTC $3630^{\mathrm{T}}$ \\
\hline & E. malodoratus & KCTC $3641^{\mathrm{T}}$ \\
\hline & E. cecorum & KCTC $3642^{\mathrm{T}}$ \\
\hline & E. saccharolyticus & KCTC $3643^{\mathrm{T}}$ \\
\hline & E. villorum & KCTC $13904^{\mathrm{T}}$ \\
\hline & E. haemoperoxidus & KCTC $13910^{\mathrm{T}}$ \\
\hline & E. moraviensis & KCTC $13911^{\mathrm{T}}$ \\
\hline & E. phoeniculicola & KCTC $3818^{\mathrm{T}}$ \\
\hline & E. solitarius & KCTC $3923^{\mathrm{T}}$ \\
\hline & E. raffinosus & KCTC $5189^{\mathrm{T}}$ \\
\hline & E. avium & KCTC $5190^{\mathrm{T}}$ \\
\hline & E. faecalis & KCTC $3206^{\mathrm{T}}$ \\
\hline & V. fluvialis & LMG $9464^{\mathrm{T}}$ \\
\hline & V. salmoninarum & LMG $11491^{\mathrm{T}}$ \\
\hline & $V$. lutrae & LMG $19537^{\mathrm{T}}$ \\
\hline
\end{tabular}

Spn9828 and Spn9802 primers were evaluated to compare PCR specificity, as described previously (Suzuki et al., 2005). The PCR was performed with $100 \mathrm{ng}$ genomic DNA as a template in a $20 \mu \mathrm{l}$ reaction mixture that contained $1 \mu \mathrm{l}$ each primer, $2 \mu \mathrm{l} 10 \times$ PCR buffer, $1 \mu \mathrm{l}$ $10 \mathrm{mM}$ dNTPs and $0.3 \mu \mathrm{l}$ Taq DNA polymerase. PCR amplification was carried out using a GeneAmp PCR system 2700 (Applied Biosystems) with the following conditions: for ply, Spn9802 and Spn9828 primers, initial denaturation at $94{ }^{\circ} \mathrm{C}$ for $2 \mathrm{~min}$ and 25 cycles of $94{ }^{\circ} \mathrm{C}$ for $10 \mathrm{~s}$,
$58{ }^{\circ} \mathrm{C}$ for $15 \mathrm{~s}$ and $72{ }^{\circ} \mathrm{C}$ for $1 \mathrm{~min}$, followed by a final extension at $72{ }^{\circ} \mathrm{C}$ for $5 \mathrm{~min}$; for $l y t A$ primers, initial denaturation at $94{ }^{\circ} \mathrm{C}$ for 2 min and 30 cycles of $94{ }^{\circ} \mathrm{C}$ for $15 \mathrm{~s}, 53{ }^{\circ} \mathrm{C}$ for $15 \mathrm{~s}$ and $72{ }^{\circ} \mathrm{C}$ for $15 \mathrm{~s}$, with a final extension at $72{ }^{\circ} \mathrm{C}$ for $5 \mathrm{~min}$; for cpsA primers, initial denaturation at $94{ }^{\circ} \mathrm{C}$ for $5 \mathrm{~min}$ and 30 cycles of $94{ }^{\circ} \mathrm{C}$ for $30 \mathrm{~s}, 58{ }^{\circ} \mathrm{C}$ for $30 \mathrm{~s}$ and $72{ }^{\circ} \mathrm{C}$ for $40 \mathrm{~s}$, followed by a final extension at $72{ }^{\circ} \mathrm{C}$ for $10 \mathrm{~min}$. The PCR products were analysed in $1.2 \%$ Seakem LE agarose gels (FMC Bioproducts) and visualized by ethidium bromide staining. 


\section{RESULTS AND DISCUSSION}

\section{Construction and screening of the S. pneumoniae SSH library}

Approximately 240 putative S. pneumoniae KCTC $5080^{\mathrm{T}}$ clones were obtained from the SSH libraries. To avoid possible false-positive or false-negative clones (Radnedge et al., 2003), all the obtained clones were further screened by reverse Southern dot-blot analysis using two differential probes: one from S. pneumoniae KCTC $5080^{\mathrm{T}}$ and the other from S. mitis KCTC $3556^{\mathrm{T}}$. A total of 34 S. pneumoniae clones were positively identified by the differential probes from S. pneumoniae KCTC $5080^{\mathrm{T}}$, but were negative using the probes for $S$. mitis KCTC $3556^{\mathrm{T}}$. Subsequent nucleotide sequencing demonstrated no redundancy among these 34 selected clones. The low number of identified clones might be due to the high genomic identity between $S$. pneumoniae KCTC $5080^{\mathrm{T}}$ and S. mitis KCTC $3556^{\mathrm{T}}$, a closely related viridans group streptococcus.

\section{Identification and annotation of S. pneumoniae- specific clones}

The identity of the 34 S. pneumoniae-specific clones was examined using BLAST homology searches. The resultant data revealed sequences highly homologous to the genomic DNA sequences of $S$. pneumoniae available in GenBank, including four transporter proteins, 10 hypothetical proteins, 14 metabolism proteins, one membrane protein and five miscellaneous proteins.

Among those tested, a single clone possessed the $492 \mathrm{nt}$ sequence specific to $S$. pneumoniae that corresponded to a partial region of the capsular polysaccharide biosynthesis (cps) gene. Previously, pneumococcal capsular polysaccharide was determined to be an essential virulence factor of $S$. pneumoniae with anti-phagocytic activity. However, capsule expression can also reduce bacterial attachment to respiratory epithelial cells and inhibit bacterial colonization (Adamou et al., 1998; Cundell et al., 1995; Weiser et al., 1994). Supporting this notion, recent electron microscopy imaging has demonstrated that $S$. pneumoniae cells that are intimately adherent to epithelial cells have thin capsule layers, indicating downregulation of capsule expression to enhance bacterial adherence (Hammerschmidt et al., 2005). The chromosomal location of the cps operon has been localized between the dexB and aliA genes (García \& López, 1997; Guidolin et al., 1994; Morona et al., 1997; Munoz et al., 1997). Although the first four genes ( $c p s A B C D)$ of the cps operon are commonly present (García et al., 1999; Jiang et al., 2001), it is known that pneumococcal capsules are structurally distinct among the different serotypes of $S$. pneumoniae (Austrian, 1981; Henrichsen, 1995).

\section{Diagnostic screening of the cpsA gene as a novel S. pneumoniae-specific marker}

To identify genomic markers unique for $S$. pneumoniae, primer sets were designed for the cpsA gene (GenBank accession no. NC_011072) (Table 2), and their specificity for $S$. pneumoniae was evaluated with a total of 134 reference strains, including $26 \mathrm{~S}$. pneumoniae, two Streptococcus pseudopneumoniae and 106 other related cocci, by gradient PCR assay. The PCR results are summarized in Table 3. One of the cpsA-specific primer sets (cpsA-382F and cpsA-735R) was highly specific to $S$. pneumoniae with the expected PCR product of $353 \mathrm{bp}$, and did not amplify any other reference strain (Fig. 1).

The lytA, ply, Spn9802 and Spn9828 primers (Table 2) have been used previously for $S$. pneumoniae screening. Because some of the related oral streptococci can harbour the $S$. pneumoniae lytA and ply genes due to horizontal gene transfer (Seki et al., 2005), a PCR method with Spn9802- and Spn9828-specific primers, in combination with lytA- and ply-specific primers, has proved useful for identifying $S$. pneumoniae. Although both the Spn9802 and Spn9828 genes encode proteins of unknown function, they are known to be specific to S. pneumoniae. Accordingly, both the specificity and efficiency of the $c p s A$-specific primers were compared with those of the primer sets for lytA, ply, Spn9802 and Spn9828 (Suzuki et al., 2005). Notably, a few false-positive amplifications with the ply, Spn9802 and Spn9828 primer sets were observed from the genomic DNAs of $S$. mitis (1/17 strains), S. pseudopneumoniae (2/2 strains), Streptococcus

Table 2. Oligonucleotide sequences used in this study

\begin{tabular}{|c|c|c|c|}
\hline Primer & Sequence $\left(5^{\prime} \rightarrow 3^{\prime}\right)$ & Amplicon size (bp) & Reference \\
\hline$c p s A-382 \mathrm{~F}$ & ACGCAACTGACGAGTGTGAC & 353 & This study \\
\hline$c p s A-735 \mathrm{R}$ & GATCGCGACACCGAACTAAT & & \\
\hline lyt $A$ antisense & TTATTCGTGCAATACTCGTGCG & & \\
\hline ply sense & ATTTCTGTAACAGCTACCAACGA & 329 & Salo et al. (1995) \\
\hline ply antisense & GAATTCCCTGTCTTTTCAAAGTC & & \\
\hline Spn9802-304R & CTAAACCAACTCGACCACСТCTTT & & \\
\hline Spn9828-19F & GGCATTGTGAATGGATTGATTG & 227 & Suzuki et al. (2005) \\
\hline Spn9828-245R & TCATGTGCATCCCAAGCTACA & & \\
\hline
\end{tabular}


Table 3. PCR screening using the primer sets specific for $S$. pneumoniae

Strains: 1, S. pneumoniae; 2, S. mitis; 3, S. oralis; 4, S. pseudopneumoniae; 5, S. pyogenes; 6, S. gordonii; 7, S. sanguinis; 8, S. parasanguinis; 9, S. constellatus; 10, S. intermedius; 11, S. anginosus; 12, Lactococcus spp.; 13, Enterococcus spp.; 14, Vagococcus spp. +, Positive; -, negative.

\begin{tabular}{|c|c|c|c|c|c|c|c|c|c|c|c|c|c|c|c|c|c|c|c|c|c|}
\hline \multirow{3}{*}{$\begin{array}{l}\text { Primer } \\
\text { set } \\
\operatorname{cps} A\end{array}$} & \multicolumn{21}{|c|}{ Result for atypical cocci strains } \\
\hline & \multicolumn{2}{|c|}{$\begin{array}{c}1 \\
(n=26)\end{array}$} & \multicolumn{2}{|c|}{$\begin{array}{c}2 \\
(n=17)\end{array}$} & \multirow{2}{*}{$\begin{array}{c}3 \\
(n=4)\end{array}$} & \multicolumn{2}{|c|}{$\begin{array}{c}4 \\
(n=2)\end{array}$} & \multirow{2}{*}{$\begin{array}{c}5 \\
(n=3)\end{array}$} & \multicolumn{2}{|c|}{$\begin{array}{c}6 \\
(n=5)\end{array}$} & \multicolumn{2}{|c|}{$\begin{array}{c}7 \\
(n=9)\end{array}$} & \multirow{2}{*}{$\begin{array}{c}8 \\
(n=8) \\
-\end{array}$} & \multirow{2}{*}{$\begin{array}{c}9 \\
(n=4)\end{array}$} & \multirow{2}{*}{$\begin{array}{c}10 \\
(n=4) \\
-\end{array}$} & \multirow{2}{*}{$\begin{array}{c}11 \\
(n=21)\end{array}$} & \multicolumn{2}{|c|}{$\begin{array}{c}12 \\
(n=14)\end{array}$} & \multicolumn{2}{|c|}{$\begin{array}{c}13 \\
(n=14)\end{array}$} & \multirow{2}{*}{$\begin{array}{c}14 \\
(n=3)\end{array}$} \\
\hline & + & + & - & - & & - & - & & - & - & - & - & & & & & - & - & - & - & \\
\hline lyt $A$ & + & - & - & - & - & - & - & - & - & - & - & - & - & - & - & - & - & - & - & - & - \\
\hline ply & + & + & - & - & - & + & + & - & - & - & - & - & - & - & - & - & - & + & - & - & - \\
\hline Spn9802 & + & + & - & - & - & + & + & - & - & + & - & + & - & - & - & - & - & - & - & - & - \\
\hline Spn9828 & + & + & - & + & - & - & + & - & - & - & - & - & - & - & - & - & - & - & - & - & - \\
\hline Subtotal & 25 & 1 & 16 & 1 & 4 & 1 & 1 & 3 & 3 & 2 & 7 & 2 & 8 & 4 & 4 & 21 & 13 & 1 & 13 & 1 & 3 \\
\hline
\end{tabular}
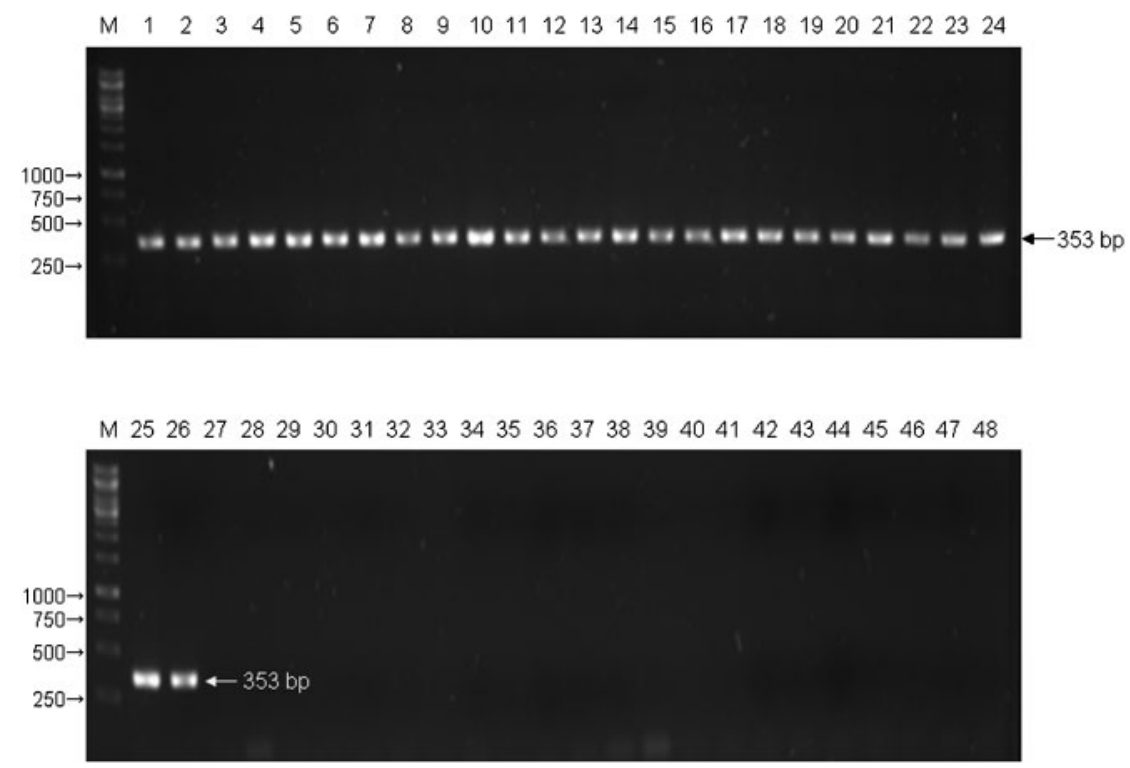

Fig. 1. Electrophoretic examination of $S$. pneumoniae-specific PCR products generated with primers cpsA-382F and cpsA735R based on the cpsA gene. Lanes: M, GeneRuler 1 kb DNA ladder (Fermentas); 1, S. pneumoniae KCTC 5080 ${ }^{\top} ; 2, S$. pneumoniae CCARM 4009; 3, S. pneumoniae CCARM 4019; 4, S. pneumoniae CCARM 4033; 5, S. pneumoniae CCARM 4109; 6, S. pneumoniae CCARM 4112; 7, S. pneumoniae CCARM 4113; 8, S. pneumoniae CCARM 4114; 9, S. pneumoniae CCARM 4115; 10, S. pneumoniae CCARM 4003; 11, S. pneumoniae CCARM 4005; 12, S. pneumoniae CCARM 4078; 13, S. pneumoniae CCARM 4079; 14, S. pneumoniae CCARM 4080; 15, S. pneumoniae CCARM 4080; 16, S. pneumoniae CCARM 4085; 17, S. pneumoniae CCARM 4088; 18, S. pneumoniae CCARM 4106; 19, S. pneumoniae CCARM 4116; 20, S. pneumoniae ChDC 4-0134; 21, S. pneumoniae ChDC 4-0749; 22, S. pneumoniae ChDC 6-4740; 23, S. pneumoniae CCARM 4081; 24, S. pneumoniae CCARM 4091; 25, S. pneumoniae CCARM 4111; 26, S. pneumoniae CCARM 4059; 27, S. pseudopneumoniae CCUG 49455 ${ }^{\top} ; 28$, S. pseudopneumoniae CCUG 48465; 29, S. mitis KCTC $3556^{\top} ; 30$, S. mitis ChDC B183; 31, S. mitis ChDC B186; 32, S. mitis ChDC B193; 33, S. mitis ChDC B194; 34, S. mitis ChDC B227; 35, S. mitis ChDC B231; 36, S. mitis ChDC B239; 37, S. mitis ChDC B242; 38, S. mitis ChDC B253; 39, S. mitis ChDC B258; 40, S. mitis ChDC B260; 41, S. mitis ChDC B279; 42, S. mitis ChDC B286; 43, S. mitis ChDC B303-1; 44, S. mitis ChDC B315; 45, S. mitis ChDC B317; 46, S. oralis KCTC $13048^{\top} ; 47$, S. oralis ATCC 9811; 48, S. oralis DSM 20379. Other Streptococcus and other bacterial (Lactococcus or Enterococcus) species are not shown because the results for these strains are the same as those seen in lanes $27-48$; no $S$. pneumoniae-specific DNA is present. The arrow shows the expected PCR product of $353 \mathrm{bp}$ common to all S. pneumoniae strains (lanes 1-26). 
gordonii (1/5 strains) and Streptococcus sanguinis, whilst one S. pneumoniae (1/26 strains) did not amplify with the lytA primers. In addition, 10 out of 21 Streptococcus anginosus strains produced amplicons of $\sim 800$ bp using the Spn9828 primers, although they should have yielded amplified products of $227 \mathrm{bp}$. The false-positive results gave amplified PCR products from unexpected species or with different sizes. This was mainly caused by non-specific primers but sometimes also by a low annealing temperature. The results indicated that these previously described S. pneumoniaespecific primers can produce both false-positive and falsenegative results.

S. pseudopneumoniae is very closely related to S. pneumoniae. Pairwise comparisons show that their $16 \mathrm{~S}$ rRNA gene sequences are almost identical, with a difference of only 5 bp between the two species, corresponding to $99.7 \%$ identity. Consistent with this finding, a recent study demonstrated that the Spn9802 and ply primer sets could not differentiate $S$. pneumoniae and the recently acknowledged species $S$. pseudopneumoniae (Abdeldaim et al., 2008). Surprisingly, the current $c p s A$-specific primer set differentiated S. pneumoniae from S. pseudopneumoniae. Thus, this primer set may be useful for discrimination of both species, as it is well known that $S$. pseudopneumoniae strains have no pneumococcal capsules, unlike S. pneumoniae (Keith et al., 2006).

Recently, several real-time PCR assays have been developed for S. pneumoniae (Abdeldaim et al., 2008; Carvalho et al., 2007; Corless et al., 2001; Greiner et al., 2001; McAvin et al., 2001; Saukkoriipi et al., 2004). Although these methods are sensitive, the results depend on the uniqueness of the applied probes. Among these, the most recent Spn9802based real-time PCR assay gave positive results with $S$. pseudopneumoniae strains (CCUG $49455^{\mathrm{T}}$ and CCUG 48465) and S. pneumoniae (Abdeldaim et al., 2008). PCR with the cPsA-specific primer set efficiently detected genomic DNA purified from all 26 S. pneumoniae strains, and no other reference strain including two S. pseudopneumoniae strains was amplified. Therefore, the cpsA gene could be used as a new marker for detection of $S$. pneumoniae using a real-time detection assay.

Because S. pneumoniae shares over $99 \% 16 \mathrm{~S}$ rRNA gene sequence identity with the other viridans group streptococci and because lateral gene transfer occurs among these species, the identification of novel genetic markers specific for S. pneumoniae is needed for accurate diagnosis and discrimination. Our findings suggest that the cpsAspecific primer set can discriminate $S$. pneumoniae from the closely related viridans group streptococci as well as other pneumococcus-like streptococci such as S. pseudopneumoniae. Moreover, the cpsA-specific primer set yielded maximal amplification at temperatures ranging from 53 to $63{ }^{\circ} \mathrm{C}$ as well as enhanced sensitivity compared with the previous Spn9802- and Spn9828-specific primers, implying a potential for novel multiplex or real-time PCR for the specific detection of $S$. pneumoniae.
In this study, SSH was used to identify the $c p s A$ gene as a novel genomic marker specific for S. pneumoniae. The cpsAspecific primer set discriminated $S$. pneumoniae from other closely related viridans group members. This new primer set may be useful for the routine diagnosis and identification of presumptive $S$. pneumoniae isolates. Alternatively, the cpsA gene can be used as an additional genomic marker specific for S. pneumoniae in combination with previously described genetic markers such as lytA, ply, Spn9802 and Spn9828.

\section{ACKNOWLEDGEMENTS}

This study was supported by a grant of the Korea Healthcare Technology R\&D Project, Ministry for Health, Welfare \& Family Affairs, Republic of Korea (A085138).

\section{REFERENCES}

Abdeldaim, G. M., Stralin, K., Olcen, P., Blomberg, J. \& Herrmann, B. (2008). Toward a quantitative DNA-based definition of pneumococcal pneumonia: a comparison of Streptococcus pneumoniae target genes, with special reference to the Spn9802 fragment. Diagn Microbiol Infect Dis 60, 143-150.

Adamou, J. E., Wizemann, T. M., Barren, P. \& Langermann, S. (1998). Adherence of Streptococcus pneumoniae to human bronchial epithelial cells (BEAS-2B). Infect Immun 66, 820-822.

Agron, P. G., Macht, M., Radnedge, L., Skowronski, E. W., Miller, W. \& Andersen, G. L. (2002). Use of subtractive hybridization for comprehensive surveys of prokaryotic genome differences. FEMS Microbiol Lett 211, 175-182.

Akopyants, N. S., Fradkov, A., Diatchenko, L., Hill, J. E., Siebert, P. D., Lukyanov, S. A., Sverdlov, E. D. \& Berg, D. E. (1998). PCR-based subtractive hybridization and differences in gene content among strains of Helicobacter pylori. Proc Natl Acad Sci U S A 95, 1310813113.

Austrian, R. (1981). Some observations on the pneumococcus and on the current status of pneumococcal disease and its prevention. Rev Infect Dis 3, S1-S17.

Ausubel, F. M., Brent, R., Kingston, R. E., Moore, D. D., Seidman, J. G. \& Struhl, K. (1993). Current Protocols in Molecular Biology, Section 2.4.1-2.4.2. New York: John Wiley \& Sons.

Carvalho, M. da G. S., Tondella, M. L., McCaustland, K., Weidlich, L., McGee, L., Mayer, L. W., Steigerwalt, A., Whaley, M., Facklam, R. R. \& other authors (2007). Evaluation and improvement of real-time PCR assays targeting $l y t A, p l y$, and $p s a A$ genes for detection of pneumococcal DNA. J Clin Microbiol 45, 2460-2466.

Corless, C. E., Guiver, M., Borrow, R., Edwards-Jones, V., Fox, A. J. \& Kaczmarski, E. B. (2001). Simultaneous detection of Neisseria meningitidis, Haemophilus influenzae, and Streptococcus pneumoniae in suspected cases of meningitis and septicemia using real-time PCR. J Clin Microbiol 39, 1553-1558.

Cundell, D. R., Weiser, J. N., Shen, J., Young, A. \& Tuomanen, E. I. (1995). Relationship between colonial morphology and adherence of Streptococcus pneumoniae. Infect Immun 63, 757-761.

Dyson, C., Barnes, R. A. \& Harrison, G. A. (1999). Infective endocarditis: an epidemiological review of 128 episodes. J Infect 38, 87-93.

Fox, G. E., Wisotzkey, J. D. \& Jurtshuk, P., Jr (1992). How close is close: $16 \mathrm{~S}$ rRNA sequence identity may not be sufficient to guarantee species identity. Int J Syst Bacteriol 42, 166-170. 
Garcia, E. \& López, R. (1997). Molecular biology of the capsular genes of Streptococcus pneumoniae. FEMS Microbiol Lett 149, 1-10.

Garcia, E., Llull, D. \& Lopez, R. (1999). Functional organization of the gene cluster involved in the synthesis of the pneumococcal capsule. Int Microbiol 2, 169-176.

Greiner, O., Day, P. J., Bosshard, P. P., Imeri, F., Altwegg, M. \& Nadal, D. (2001). Quantitative detection of Streptococcus pneumoniae in nasopharyngeal secretions by real-time PCR. J Clin Microbiol 39, 3129-3134.

Guidolin, A., Morona, J. K., Morona, R., Hansman, D. \& Paton, J. C. (1994). Nucleotide sequence analysis of genes essential for capsular polysaccharide biosynthesis in Streptococcus pneumoniae type 19F. Infect Immun 62, 5384-5396.

Hammerschmidt, S., Wolff, S., Hocke, A., Rosseau, S., Muller, E. \& Rohde, M. (2005). Illustration of pneumococcal polysaccharide capsule during adherence and invasion of epithelial cells. Infect Immun 73, 4653-4667.

Henrichsen, J. (1995). Six newly recognized types of Streptococcus pneumoniae. J Clin Microbiol 33, 2759-2762.

Jiang, S. M., Wang, L. \& Reeves, P. R. (2001). Molecular characterization of Streptococcus pneumoniae type 4, 6B, 8, and 18C capsular polysaccharide gene clusters. Infect Immun 69, 1244-1255.

Kawamura, Y., Whiley, R. A., Shu, S. E., Ezaki, T. \& Hardie, J. M. (1999). Genetic approaches to the identification of the mitis group within the genus Streptococcus. Microbiology 145, 2605-2613.

Keith, E. R., Podmore, R. G., Anderson, T. P. \& Murdoch, D. R. (2006). Characteristics of Streptococcus pseudopneumoniae isolated from purulent sputum samples. J Clin Microbiol 44, 923-927.

Kim, W., Kim, J.-Y., Cho, S.-L., Nam, S.-W., Shin, J.-W., Kim, Y.-S. \& Shin, H.-S. (2008). Glycosyltransferase - a specific marker for the discrimination of Bacillus anthracis from the Bacillus cereus group. J Med Microbiol 57, 279-286.

McAvin, J. C., Reilly, P. A., Roudabush, R. M., Barnes, W. J., Salmen, A., Jackson, G. W., Beninga, K. K., Astorga, A., McCleskey, F. K. \& other authors (2001). Sensitive and specific method for rapid identification of Streptococcus pneumoniae using real-time fluorescence PCR. J Clin Microbiol 39, 3446-3451.

Morona, J. K., Morona, R. \& Paton, J. C. (1997). Characterization of the locus encoding the Streptococcus pneumoniae type 19F capsular polysaccharide biosynthetic pathway. Mol Microbiol 23, 751-763.

Morrison, K. E., Lake, D., Crook, J., Carlone, G. M., Ades, E., Facklam, R. \& Sampson, J. S. (2000). Confirmation of $p s a A$ in all 90 serotypes of Streptococcus pneumoniae by PCR and potential of this assay for identification and diagnosis. J Clin Microbiol 38, 434-437.

Munoz, R., Mollerach, M., Lopez, R. \& García, E. (1997). Molecular organization of the genes required for the synthesis of type 1 capsular polysaccharide of Streptococcus pneumoniae: formation of binary encapsulated pneumococci and identification of cryptic dTDPrhamnose biosynthesis genes. Mol Microbiol 25, 79-92.

Nagai, K., Shibasaki, Y., Hasegawa, K., Davies, T. A., Jacobs, M. R., Ubukata, K. \& Appelbaum, P. C. (2001). Evaluation of PCR primers to screen for Streptococcus pneumoniae isolates and $\beta$-lactam resistance, and to detect common macrolide resistance determinants. J Antimicrob Chemother 48, 915-918.

O'Neill, A. M., Gillespie, S. H. \& Whiting, G. C. (1999). Detection of penicillin susceptibility in Streptococcus pneumoniae by $p b p 2 b$ PCRrestriction fragment length polymorphism analysis. J Clin Microbiol 37, 157-160.
Radnedge, L., Agron, P. G., Hill, K. K., Jackson, P. J., Ticknor, L. O., Keim, P. \& Andersen, G. L. (2003). Genome differences that distinguish Bacillus anthracis from Bacillus cereus and Bacillus thuringiensis. Appl Environ Microbiol 69, 2755-2764.

Rozen, S. \& Skaletsky, H. (2000). Primer3 on the WWW for general users and for biologist programmers. Methods Mol Biol 132, 365-386.

Salo, P., Ortqvist, A. \& Leinonen, M. (1995). Diagnosis of bacteremic pneumococcal pneumonia by amplification of pneumolysin gene fragment in serum. J Infect Dis 171, 479-482.

Saukkoriipi, A., Leskela, K., Herva, E. \& Leinonen, M. (2004). Streptococcus pneumoniae in nasopharyngeal secretions of healthy children: comparison of real-time PCR and culture from STGGtransport medium. Mol Cell Probes 18, 147-153.

Seki, M., Yamashita, Y., Torigoe, H., Tsuda, H., Sato, S. \& Maeno, M. (2005). Loop-mediated isothermal amplification method targeting the lytA gene for detection of Streptococcus pneumoniae. J Clin Microbiol 43, 1581-1586.

Stackebrandt, E. \& Goebel, B. M. (1994). Taxonomic note: a place for DNA-DNA reassociation and 16S rRNA sequence analysis in the present species definition in bacteriology. Int J Syst Bacteriol 44, 846849.

Stackebrandt, E., Witt, D., Kemmerling, C., Kroppenstedt, R. \& Liesack, W. (1991). Designation of streptomycete $16 \mathrm{~S}$ and 23S rRNAbased target regions for oligonucleotide probes. Appl Environ Microbiol 57, 1468-1477.

Suzuki, N., Seki, M., Nakano, Y., Kiyoura, Y., Maeno, M. \& Yamashita, Y. (2005). Discrimination of Streptococcus pneumoniae from viridans group streptococci by genomic subtractive hybridization. J Clin Microbiol 43, 4528-4534.

Suzuki, N., Yuyama, M., Maeda, S., Ogawa, H., Mashiko, K. \& Kiyoura, Y. (2006). Genotypic identification of presumptive Streptococcus pneumoniae by PCR using four genes highly specific for S. pneumoniae. J Med Microbiol 55, 709-714.

Thompson, J. D., Gibson, T. J., Plewniak, F., Jeanmougin, F. \& Higgins, D. G. (1997). The CLUSTAL_X windows interface: flexible strategies for multiple sequence alignment aided by quality analysis tools. Nucleic Acids Res 25, 4876-4882.

Verhelst, R., Kaijalainen, T., De Baere, T., Verschraegen, G., Claeys, G., Van Simaey, L., De Ganck, C. \& Vaneechoutte, M. (2003). Comparison of five genotypic techniques for identification of optochin-resistant pneumococcus-like isolates. J Clin Microbiol 41, 3521-3525.

Weiser, J. N., Austrian, R., Sreenivasan, P. K. \& Masure, H. R. (1994). Phase variation in pneumococcal opacity: relationship between colonial morphology and nasopharyngeal colonization. Infect Immun 62, 2582-2589.

Whatmore, A. M., Efstratiou, A., Pickerill, A. P., Broughton, K., Woodard, G., Sturgeon, D., George, R. \& Dowson, C. G. (2000). Genetic relationships between clinical isolates of Streptococcus pneumoniae, Streptococcus oralis, and Streptococcus mitis: characterization of "atypical" pneumococci and organisms allied to S. mitis harboring S. pneumoniae virulence factor-encoding genes. Infect Immun 68, 1374-1382.

Willcox, M. D., Drucker, D. B. \& Hillier, V. F. (1988). In-vitro adherence of oral streptococci in the presence of sucrose and its relationship to cariogenicity in the rat. Arch Oral Biol 33, 109-113. 